\title{
BMJ Open Quality Driving quality improvement with a massive open online course (MOOC)
}

\author{
Cheryl Guest, ${ }^{1}$ Philip Wainwright, ${ }^{1}$ Margaret Herbert, ${ }^{1}$ lain Murray Smith (D) ${ }^{2}$
}

\begin{abstract}
To cite: Guest $C$, Wainwright $P$, Herbert $\mathrm{M}$, et al. Driving quality improvement with a massive open online course (M0OC). BMJ Open Quality 2021;10:e000781. doi:10.1136/ bmjoq-2019-000781
\end{abstract}

Received 10 September 2019 Revised 11 February 2021 Accepted 22 February 2021
Check for updates

(C) Author(s) (or their employer(s)) 2021. Re-use permitted under CC BY-NC. No commercial re-use. See rights and permissions. Published by BMJ.

${ }^{1}$ Improvement Directorate, NHS England Sustainable Improvement Team, Leeds, UK ${ }^{2}$ Improvement Capability Building, NHS England, Newcastle Upon Tyne, UK

Correspondence to

Cheryl Guest;

cherylguest@nhs.net

\section{ABSTRACT}

Background Quality improvement (QI) is a priority for national regulatory bodies in health and care in the UK. However, many health and care staff do not know where to go for support in gaining the required skills and knowledge in QI. This paper reviews Improvement Fundamentals, a massive open online course (M00C), designed to address this gap, run by an improvement team in the national regulatory body.

Methods In 2015, National Health Service (NHS) Improving Quality (subsequently the sustainable improvement team in NHS England) established Improvement Fundamentals: a programme of online, selfdirected courses in QI for those involved in heath or social care. The programme ran in two cycles: twice in 2015 , followed by a re-launch in 2018 (this programme also ran into 2019). A mixed-methods evaluation was carried out of the 2015 programme involving surveys, interviews and social listening. The 2018-2019 programme was evaluated using post-course surveys of participants and activity data from the platform.

Outcomes Since the start of the 2015 programme, 604 improvement projects have been developed, run and submitted for formal assessment, with some demonstrating clear improvements in services. Themes from participant feedback on both programmes have included improved understanding of QI tools and methods; greater energy for Ql; a greater sense of community and connectedness in participants' work and increased confidence in using $\mathrm{Ql}$ tools and techniques.

Discussion Both programmes delivered benefits for participants, and the team's investment in improvement skills on these programmes has helped to increase capability for future change endeavours. The collaborative nature of the programmes has been key to their successes.

Conclusion Improvement Fundamentals demonstrates that M00Cs can be instrumental in driving forward improvements in health and care. The programmes may have utility as a model for future MOOCs, both in QI and other topics, to help drive further improvements in health and care.

\section{BACKGROUND}

Quality improvement (QI) has been defined as 'the systematic use of methods and tools to try to continuously improve quality of care and outcomes for patients'. UK national regulatory bodies in health and care have identified knowledge of QI as a key condition common to high performing systems. ${ }^{2} \mathrm{QI}$ is playing a vital role in enhancing services not just nationally, but globally in health and care today. The National Health Service (NHS) Long Term Plan (p.111) argues that QI is 'an evidence-based approach for improving every aspect of how the NHS operates', ${ }^{3}$ stating that delivery of the plan will rely on local health systems having the capability to implement change effectively.

There is a clear need and desire to improve capability in QI. However, there is no single agreed way of achieving this. It has become apparent that the education of staff does not adequately prepare them for the changing world of health and care. ${ }^{4}$ In particular, staff working in health and care are often not equipped to carry out continuous QI and do not know where to go to access training and support. A review in the English NHS found that arrangements for improvement and leadership development were insufficient, ${ }^{5}$ and recommended a digital platform for e-learning to drive enhanced skills and capability in the workforce.

E-learning programmes, in particular massive open online courses (MOOCs), are increasing in number in health and care. Traditional models of face-to-face learning are becoming less practical for learners working across diverse and geographically spread settings. ${ }^{6}$ Spector argued that 'MOOCs can make a significant contribution in the context of a tightly focused short course on a topic that is very well-defined with mostly declarative knowledge (facts and concepts) and simple rules and procedures'. 7 The use of MOOCs, however, has been a matter of debate with frequent poor retention rates ${ }^{8}$ and feelings of isolation among students reported. ${ }^{9}$ There remains a lack of evidence of the efficacy of MOOCs in health and care.

This article reviews the impact of a community-focused, introductory-level MOOC, 'Improvement Fundamentals', in QI run between April 2015 and March 2019 by an improvement team embedded in a UK national regulatory body (initially NHS Improving Quality and subsequently the sustainable improvement team in NHS 
England and NHS Improvement). NHS England and NHS Improvement leads the NHS in England. The course was specifically targeted at a global audience of learners and the single eligibility criteria for access to the course was for learners to have an interest in QI in health and care.

\section{METHODS}

In 2015, NHS Improving Quality (subsequently the sustainable improvement team in NHS England) established Improvement Fundamentals: a programme of online, self-directed short courses in QI for those involved in heath or social care services irrespective of job role, employer or geographical location. The courses were facilitated by improvement leaders from NHS England who guided participants from across the world through initiating their own small-scale improvement project and combined improvement theory with practical tools and support.

The programme was commissioned by NHS England, to be developed by an internal team with QI and accessible learning expertise. The programme was designed to support people working in, or with, health or social care internationally who were enthusiastic about driving improvements in their local service and structured to help those individuals who were keen to put their improvement ideas into practice, but were not sure how to go about it.

The design team aimed to facilitate a capabilitybuilding offer across health and care communities at scale and pace, innovate, prototype and share best practice improvement approaches, resources and infrastructure provide expert advice, coaching and consultancy support, and thought leadership and facilitate networking, collaboration and peer support across improvement landscape via the Improvement Fundamentals Programme.

The programme was run in two cycles: twice in 2015, followed by a re-launch in 2018 by the accessible learning team in NHS England (part of the sustainable improvement team). The 2015 programme was run on the Blackboard platform, and the course was made up of four linear modules $(\mathrm{QI}$ theory, QI tools, QI measures and QI spread and sustainability). The course content was developed in accordance with recommendations outlined in the Quality Improvement-training for better outcomes (2016) document (pp65-68) by the Academy of Medical Royal Colleges. ${ }^{10}$

The programme team worked with an in-house graphic designer and video producer to develop a unique suite of resources based on the team's own knowledge and expertise. In total, 14 new videos were developed, a further 20 videos were re-purposed, and both sets of videos were supplemented with articles, discussions and practical exercises.

In response to participant feedback, the 2018 version was divided into 'stand-alone' 'mini-courses', rather than the linear courses taken one after the other in the original programme, and participants could choose which mini-courses to take part in and in what order. This approach allowed the learners to have greater flexibility over their own learning journey. Feedback also indicated that participants wanted the platform to facilitate more peer-to-peer engagement. Therefore, the team entered into a partnership with the software company HT2, and procured the social learning platform Curatr in 2018, to replace Blackboard.

Each new mini-course was run once in 2018, and again in March 2019. The programme consisted of five short modules per mini-course, covering key topics in QI. Both programmes were offered free-of-charge to participants and the 2018-2019 programme was continuing professional development (CPD) accredited via the CPD Certification Service.

A mixed-methods evaluation was carried out of the 2015 programme involving surveys, interviews and social listening. This included semi-structured interviews with 28 programme participants. Feedback was triangulated with pre-course and post-course surveys of the overall course participants, routine course activity data and social media analysis. One thousand six hundred and twentyseven students completed the pre-MOOC surveys, and of these, $154(9.5 \%)$ completed the post-MOOC surveys in spring and autumn 2015 combined.

The 2018-2019 programme was evaluated using postcourse surveys of participants and activity data from the platform. A total of 1575 survey responses were received (37\% of those who participated in the programme).

The programme was delivered through videos, articles, discussions, templates and practical exercises. Each course was facilitated live for a week, following which participants were encouraged to work on their own workplace project. The course was then left open for several weeks to enable participants to catch up if they needed to.

The programme was designed around three main characteristics: short, practical and collaborative. To make it easier to connect with colleagues, the programme used comments forums on the platform ('social spaces') and Twitter discussions ('tweet chats') to encourage the development of an active Twitter community of participants.

The programme also offered learners the opportunity to establish a small improvement project in their own workplace that was supported through guided exercises and templates from the course. Learners were then able to write up the results of this project into a case study and apply for health improvement knowledge and experience resource (HIKER) status.

\section{OUTCOMES}

Both programmes were successful at creating a measurable impact on participants and their improvement projects.

Since the start of the 2015 programme, 604 projects have been developed and run by learners who chose to write up their projects to apply for HIKER status. HIKER status was the in-house process for the recognition of completed 


\begin{tabular}{|c|c|c|c|}
\hline & \multicolumn{2}{|l|}{ Year } & \multirow[b]{2}{*}{ Aggregate } \\
\hline & 2015 & 2018 & \\
\hline Number of learners enrolled & 3295 & 8927 & 12222 \\
\hline Learners who completed all modules* & $249(11 \%)$ & $1561(36 \%)$ & $1810(27 \%)$ \\
\hline
\end{tabular}

Data presented as $\mathrm{n}(\%)$ unless otherwise indicated.

${ }^{*}$ Completion rate calculated as a percentage of learners who started the course.

small-scale improvement projects that were written up as case studies. There are also many more successful projects that have been run using the HIKER methodology that were not submitted for formal assessment. One participant credited the programme for helping them to reduce waiting times for diagnostic services in a hospital; another stated that it enabled them to involve patients and carers more meaningfully in clinical audit projects and a third said it helped them to implement a change that reduced the number of patients lost to follow-up in a clinical research project.

Themes from participant feedback on both programmes have included improved understanding of QI tools and methods; greater energy for QI and a greater sense of community and connectedness in participants' work. It also gave participants more confidence in using QI tools and techniques-one participant commented: 'I have successfully applied for a fixed term contract with the PMO office, I believe this course had a positive effect on my application, and it certainly gave me the confidence to apply.'

Following the 2018-2019 programme, 88\% of respondents said the programme improved their ability to get started on their improvement project, $92 \%$ said they were able to apply what they learnt on the programme and
$79 \%$ said they were already putting their learning into practice. Learner satisfaction with the course was equally scored highly across both versions of the programme with course engagement increasing steadily between the first and second versions of the course. See tables 1 and 2 .

During both programmes, an international community emerged, both on the learning platforms and on Twitter (the programme's Twitter account now has over 2500 followers).

After the 2015 programme, $52 \%$ of respondents from the 2015 programme felt that the programme connected them with others working in QI. This rose to $65 \%$ for the 2018-2019 programme.

Since the start of the CPD accreditation process in 2018, 1633 CPD points have been allocated to learners to support their CPD.

\section{DISCUSSION}

Both programmes delivered benefits for participants, and the team's investment in improvement skills on these programmes has helped to increase capability for future change endeavours. However, limited time has passed since the 2018-2019 programme and so it is not possible to gauge the full impact of the programme.

Table 2 Learners' satisfaction with the course

\begin{tabular}{|c|c|c|}
\hline \multirow{2}{*}{ Statements } & \multicolumn{2}{|c|}{$\begin{array}{l}\text { Participants who agreed or strongly agreed to } \\
\text { the statements in post-course surveys }\end{array}$} \\
\hline & \multicolumn{2}{|l|}{ Year } \\
\hline I learnt a lot from taking part in the MOOC & $127(86 \%)$ & $1290(81 \%)$ \\
\hline $\begin{array}{l}\text { What I have learnt from taking the course will make a real difference in my } \\
\text { workplace }\end{array}$ & 116 (78\%) & $1289(81 \%)$ \\
\hline $\begin{array}{l}\text { The course improved my understanding of quality improvement in health } \\
\text { and social care }\end{array}$ & $131(89 \%)$ & $1402(88 \%)$ \\
\hline
\end{tabular}

Data presented as $\mathrm{n}(\%)$ unless otherwise indicated.

*Some missing data: this statement was introduced midway into 2018/2019 course. \% calculation based on 781 learners who responded to this question.

MOOC, massive open online course. 
Completion rates on the 2018-2019 programme were higher than the average for an MOOC-one study found an average completion rate of $12.6 \%$ on 221 MOOCs. ${ }^{11}$ The high completion rate could well be down to the short, practical and collaborative nature of the programme, and this is borne out in participant feedback.

The social and collaborative nature of the programmes has been key to their successes, and the increase in the percentage of participants feeling the programme connected them to others working in QI may well have been caused by the more social aspects of the 2018-2019 programme, helped by the more collaborative nature of the Curatr platform.

One limitation of this study is that it is not always possible to make a direct link between the work of the programme and successful improvement carried out by participants, as many other factors come into play. To help mitigate this, we have only used examples in which participants themselves directly ascribe improvements to the programme itself although many more exist.

\section{CONCLUSION}

Improvement Fundamentals demonstrates that an MOOC can be instrumental in driving forward improvements in health and care. The programme's approach of being short, practical and collaborative supports Spector's (2014) argument that MOOCs can be successful if they are tightly focused and support simple rules and procedures. The success and longevity of the programme, offered as a free online programme of QI learning, demonstrates that alternatives to face-to-face learning models can be effective and sustainable. Furthermore, the programme may have utility as a model for future MOOCs, both in QI and other topics, to help drive further improvements in health and care.

Acknowledgements We would like to thank Jönköping University and Qulturum in Sweden, who co-produced and co-ran the 2015 programme with us. We would also like to thank Imperial College London, who carried out the main aspects of the evaluation of the 2015 programme on our behalf.

Contributors $\mathrm{CG}$ and $\mathrm{MH}$ were responsible for the planning, conduct and reporting of the work described. CG and PW were responsible for writing the article and contributing to data analysis. CG, IMS and MH contributed to the writing and revision of the article.

Funding The authors have not declared a specific grant for this research from any funding agency in the public, commercial or not-for-profit sectors.

Competing interests CG and MH work as improvement professionals in the NHS and led the design and delivery of the improvement fundamentals M00C. IMS works as an improvement and transformation professional in the NHS and had oversight of the programme. PW works as a communications professional in the NHS and worked on the evaluation of improvement fundamentals.
Patient and public involvement Patients and/or the public were not involved in the design, or conduct, or reporting, or dissemination plans of this research.

Patient consent for publication Not required.

Ethics approval The Health Research Authority online decision tool was used to determine that NHS research ethics was not required for the study as it was considered to be evaluation of service improvement.

Provenance and peer review Not commissioned; externally peer reviewed.

Data availability statement All data relevant to the study are included in the article.

Open access This is an open access article distributed in accordance with the Creative Commons Attribution Non Commercial (CC BY-NC 4.0) license, which permits others to distribute, remix, adapt, build upon this work non-commercially, and license their derivative works on different terms, provided the original work is properly cited, appropriate credit is given, any changes made indicated, and the use is non-commercial. See: http://creativecommons.org/licenses/by-nc/4.0/.

ORCID iD

lain Murray Smith http://orcid.org/0000-0003-1138-2166

\section{REFERENCES}

1 Alderwick $\mathrm{H}$, Charles A, Jones B. Making the case for quality improvement: lessons for NHS boards and leaders, 2017The King's Fund and The Health Foundation. Available: https://www.kingsfund. org.uk/publications/making-case-quality-improvement\#what-do-wemean-by-qi

2 NHS Improvement. Developing people - improving care. London; 2016. https://improvement.nhs.uk/documents/542/Developing People-Improving_Care-010216.pdf

3 NHS England and NHS Improvement. The NHS long term plan. London; 2019. https://www.longtermplan.nhs.uk/wp-content/ uploads/2019/01/nhs-long-term-plan-june-2019.pdf

4 Cooke M, Ironside PM, Ogrinc GS. Mainstreaming quality and safety: a reformulation of quality and safety education for health professions students. BMJ Qual Saf 2011;20 Suppl 1:i79-82.

5 Smith E. Review of centrally funded improvement and leadership development functions, 2015NHS England. Available: https://www. leadershipacademy.nhs.uk/wp-content/uploads/dlm_uploads/2017/ 10/improv-Idrshp-dev-rev-sept15.pdf

6 Sneddon J, Barlow G, Bradley S, et al. Development and impact of a massive open online course (MOOC) for antimicrobial stewardship. $J$ Antimicrob Chemother 2018;73:1091-7.

7 Spector JM. A Critical Look at MOOCs. In: Jemni M, Kinshuk KM, eds. Open education: from OERs to MOOCs. Lecture notes in educational technology. Berlin, Heidelberg: Springer, 2017. https:// link.springer.com/chapter/10.1007/978-3-662-52925-6_7

8 Fricton J, Anderson K, Clavel A, et al. Preventing chronic pain: a human systems Approach-Results from a massive open online course. Glob Adv Health Med 2015;4:23-32.

9 MacNeill H, Telner D, Sparaggis-Agaliotis A, et al. All for one and one for all: understanding health professionals' experience in individual versus collaborative online learning. J Contin Educ Health Prof 2014;34:102-11.

10 Academy of Medical Royal Colleges. Quality improvement - training for better outcomes, 2016. Available: https://www.aomrc.org.uk/ reports-guidance/quality-improvement-training-better-outcomes/

11 Jordan K. Massive open online course completion rates revisited: assessment, length and attrition. The International Review of Research in Open and Distributed Learning 2015;16.

12 Health Research Authority. Is my study research? 2017. Available: http://www.hra-decisiontools.org.uk/research/ [Accessed Mar 2020]. 